\section{Contributors to Volume 46, Number 3}

Samuel Gyasi Obeng is in the Linguistics Department at Indiana University, Bloomington 47405 . His article on hypocoristic day names in Akan was published in Multilingua and an article on dog names will soon appear in the International Journal of the Sociology of Language. $\mathrm{He}$ is currently working on a book on African personal names. email: sobeng@indiana.edu

Ladislav Zgusta is a frequent contributor to this and other journals concerned with names or language. $\mathrm{He}$ is currently at the Center for Advanced Study at the University of Illinois, Urbana 61801-3029. He is one of the editors of, and also a contributor to, the multi-volume Name Studies, published in 1995. email: 1-zgusta@uicu.edu

\section{Akan Death-Prevention Names: A Pragmatic and Structural Analysis}

\section{Samuel Gyasi Obeng \\ Indiana University}

This paper discusses the content and types of Akan death-prevention names. It provides a structural linguistic analysis of the morphology of these names and presents a socio- and ethnolingustic account of the deathprevention names as they function within Akan communication. The paper also classifies the names according to their structures. Death-prevention names are shown to be meaning ful and to refer to the lives of both their bearers and the name-givers.

\section{Introduction}

Names in Akan, as in other cultures, are pointers to their users' hopes, dreams and aspirations; they may reflect their users' geographical environment as well as their fears, religious beliefs, and philosophy of life and death. Children's names may even provide insights into important cultural or socio-political events at the time of their birth.

For an Akan child of Ghana, as with the Igbo, Hausa, and Yoruba of Nigeria, and the WaSwahili of Tanzania, the circumstances surrounding a child's birth may be considered when a name is being chosen. Factors such as the day of the week of the birth, the season of the year, and even the attitude of the parents may be caught up in an Akan child's name (Madubuike 1974;1994; Zawawi 1993). In fact, as Chuks-orji (1972) points out, the time of day (dawn, morning, dusk, afternoon, evening, night), the specific circumstances relating to the child and to the child's family as well as the gender of the child all play significant roles in the overall naming process and in the actual name given. Among the Luo of Kenya a girl born in the middle of the road may be called Ayo; a boy born in the middle of the road may be called Oyo (Okwany 1998). (In these names $a$ - is a feminine prefix, $o$ - is a masculine prefix, and $-y o$ '[on the] way' is the root.) In Akan, a boy or a girl who was

Names 46.3 (September 1998):163-187

ISSN:0027-7738

(C) 1998 by The American Name Society 
born in the middle of the road may be called simply Akwantimfi 'middle of the road'. 1

Some sub-Saharan African ethnic groups also change or add to their names when their social, economic, cultural, or political status changes (Ebeogu 1993; Madubuike 1974; Sarpong 1974; Ubahakwe 1981). African naming practices thus reveal important insights into the sociopolitical roles and relationships of the individuals thus named (Suzman 1994.) A person may be named Akuwudike 'wealth is power' in Igbo or Odefo 'the wealthy one' in Akan to reflect the acquisition of wealth.

In many African societies, a name is perceived as an important indicator of the bearer's behavior and as a pointer to the name-bearer's past, present, and future accomplishments. As Zawawi $(1993,6)$ notes, a name constructs a person because the name one bears may create an attitude in those who hear it even before they meet the name-bearer. African names not only point to the dreams and expectations of the name givers but also of the name-bearers. It is not surprising, therefore, that the Akan have the saying Yede wo to Temanmuhunu a, woremmo bra biara. 'If you are named "Live-in-a-place-doing-nothing," you'll never lead a fruitful life'. Like the Akan, the Igbo also have a special communicative maxim about the power inherent in names: Eji aha abagbu mmadu 'One's fate can be ruined by the kind of name given to the person at birth' (Ebeogu 1993, 133). Cognizant of the fact that in some African societies names are viewed as designations for the sum total of a person, and capable of shaping the person's future accomplishments, great care is taken to make personal names "context-sensitive"-the name must not only be culturally appropriate, it must also suit the overall circumstances surrounding the child's birth, and the totality of the nuclear and extended family's experiences and sometimes even the experiences of the entire ethnic group (Asante 1995).

\section{Akan Naming}

In Akan society, names are not mere labels showing which person (particularly, which father) is responsible for a child's birth. Unlike in Western societies where children usually take their father's last name, in Akan society, children have their own names. Only a very few people (in particular those who have been through formal Western education) take their father's name and juxtapose it to their own name, contrary to Akan naming practices.
Furthermore, in Akan society, there is always a close identity between the name and the name bearer such that the name links to the name-giver's overall experiences. As Sarpong (1974) rightly points out, one is not simply called $\mathrm{X}$, one is $\mathrm{X}$. At formal gatherings in Akan society, for example, it is not uncommon to hear someone introduce another by saying ne din ne ne honam se 'that one's name is a reflection of his/her personality and his/her being'. People may be held accountable for the concept, idea, or content of their names; it is therefore common to hear such an utterance as Yaw Barima paa ara na woye hufo sei? 'How come that you're called Yaw, the brave one, and yet you exhibit such great cowardice'? if a Thursday-born Akan male, who is expected to be brave, turns out to be a coward.

A child gets one of its first names from the name of the day of the week on which it is born. For example, I was born on Monday, so my day-name is Kwadwo 'a male person born on Monday'. ${ }^{2}$ Each day-name has an associated by-name, a kind of appellation; mine is Okoto. Thus, individuals get two names from the day of their birth. The Akan also have birth order names. Being the sixth and last born, I am called Nsia and Kaakyire respectively. The name Kaakyire is given to a person later in life, especially when the parents are certain that they will not or cannot have any more children. In addition to these names, every Akan has a proper name, a name given after an important person, usually within, but occasionally outside one's father's lineage. For example, my proper name is Obeng because I was named after Obenewaa, my father's aunt. Some Akans also have a brofodin, an English name or Biblical name; mine is Samuel. ${ }^{3}$ It is also a common practice for educated Akans to take the name of their father and juxtapose it to their other names. For example, my middle name, Gyasi, is my father's name.

\section{Death-Prevention Names}

If a couple has lost many of their children at birth or shortly thereafter, they may give a child a "death-prevention" name. Deathprevention names are thought to have the ability to assure the namebearer's survival. Death-prevention names are structurally different from other Akan names. General Akan names morphologically distinguish male names from female names (for example Obeng/Obenewaa, Pipim/Pipimaa), but with death-prevention names, both males and females have the same name form. Beyeeden can be a male's or female's name. 
In Akan society, it is believed that every Akan has two sets of parents-biological and spiritual. Like God, the ancestors, and other supernatural beings, a child's spiritual parents have the power to decide whether that child survives or goes back to the spirit world (that is, dies). If, for whatever reason, one's spiritual parents decide to punish one's biological parents, then awomawu 'child death' is visited upon them. Such couples may have as many children as they wish but not a single one will survive. The children may die at birth or before they turn five. It is also believed that if parents repeatedly lose children it is the same child who plays akoneaba-that is, who successively comes into and goes out of the world with the intent of frustrating its biological parents.

In order to prevent the death of a child, the women present at the birth give the child a death-prevention name. Sarpong (1974) refers to Akan death-prevention names as "funny" names because they are not normal Akan names. They sometimes refer to objects or animals considered by the Akan to be destructive (e.g., goat) or unclean (e.g., trash). The Luo of Kenya (who are unrelated to the Akan) believe that such survival names as $A k u m u$ and $O k u m u$ 'to throw away' serve to fool the Death God and thereby make the infant survive (Okwany 1998). In Akan society, the funnier the name, the better it is said to be because it is thought that with the funny name, the child will be ashamed to go back to the spirit world (Sarpong 1974).

Furthermore, by giving children death-prevention names, the children's biological parents hope that even if the members of the spirit world recognize the children eventually, they will be so angry (because of the ugly nature of the death-prevention name) that they will not call the child to the spirit world. Specifically, the spiritual parents will be "incapacitated" by the death-prevention names and this will enable the child to live ${ }^{4}$ Like the Akan, the Luo use death-prevention names to deceive, to trick, and to outwit the death god, thereby diverting his attention form the child and subsequently letting the child live (Auma Okwany, personal communication). The close relationship between naming and infant mortality is also found among the Ngoni of Nigeria where a child may be referred to as "it" or "thing" or named Chabwera 'It has arrived'. A proper name is not given until the parents are certain that the child will survive (Chuks-orji 1972).
Death-prevention names protect children from death in a number of ways. They serve to:

1. hide the children's identities and therefore make it impossible for their spiritual parents to recognize them and snatch them from the real world. For example, a name like Wangara will safely hide a child's identity because it is not an Akan name; it refers to someone from the Wali ethnic group;

2. shame the children and thus reprimand them by letting them know that the parents and name-givers are aware of and displeased with their successive comings and goings in and out of the world. Beyeeden 'What did you come to do', for example, tells the bearer that its parents are aware of the child's actions and are displeased with it;

3. command or plead with the children and with the forces or powers that be, to let the children live. Thus, through death-prevention names like Bagyina 'If you have come, then stay' and Oyinka 'May this one remain', the name-givers recognize the power of the children to make a decision to live or die;

4. reveal to the children the parents' emotional or psychological state, especially their frustration. For example, Semereka 'If I should tell' or Kwandaho 'You may leave' show immense anger and frustration on the part of the name-givers because they believe it is the same child who is causing their emotional stress by coming and going between the two worlds;

5. reveal to the children the joy and goodness in life and consequently give them a reason to live. The Yoruba death names Durojaye 'Stay and enjoy life' and Kalejaye 'Sit down and enjoy life' suggests to the child that there is joy in life;

6. reveal both the good and bad faces of death. Death-prevention names thus reveal death's ability to spare one's life, its ability to show compassion and to pardon. However, they also show death's ruthlessness. For example, the Igbo death name Onwughara 'May death forgive' presuposses that death has the ability to forgive whereas Onwudiwe 'Death is wicked' shows death's ruthlessness;

7. demonstrate that even though death is powerful, it is not allknowing because, through naming, it can be tricked by humans. As one of my informants, Akroma 'hawk', pointed out, "Through my deathprevention name, death was 'dazed' and could not recognize me; that's 


\section{Names 46.3 (September 1998)}

how I survived." (The ability to trick death is also noted by Oduyoye [1982] in Yoruba society, where the name Kusmo means 'Death could not recognize him'); and

8. demonstrate that death has the power to take vengeance for an individual's action. In Igbo, the death name Onwughara 'Death, please forgive' suggests that death has the power to punish one if it so desires.

Among the Igbo of Nigeria, Umunna (1968) notes that a deathprevention name may show the greatness of death; for example, the name Onwuke means 'Death is greater than man'. The name-givers may also show their defiance of death by naming a child Onwuma 'Death may do as he pleases' or Onwudinjo 'Death is unkind'. In Akan society, the above "attributes" of death often appear in chants. It is common to hear dirge singers say owuo ti mu ye den 'Death is wicked'.

According to Thipa (1983), a death-name may show that nature has a way of compensating a couple who have lost their children; Puseletson in Sesotho and Mbyiselo in Xhosa (southern Africa) mean 'recompense', suggesting something like 'a reward for our dead child(ren)'.

Use of death-prevention and related names (e.g., death names, penthonyms, necronyms and so forth), are found in a number of societies in Asia and the Americas as well as in Africa. For example, among the Arapaho, a sick infant's name is changed in order to trick death and thus enable the child to recover and live (Lowie 1963). According to Strathern (1970), among the Wiru of Asia, if someone dies of, say, poisoning, the child born next is called Toema 'poison' in order to mark the death of the deceased. Such a name expresses grief for the death of the deceased and also acts as a reminder to the deceased's kinsfolk to secure revenge by counter-poisoning.

Wiru penthonyms, like some Akan death-prevention names, may express grief. These sorrow-names may be a direct statement of sorrow, refer to a wound or to circumstances at burial. For example, the Wiru name Tata-me ('leaf' + female suffix) refers to the banana leaves used to wrap the deceased; the Akan death-prevention name Sieamono 'Bury him alive' refers to the speed involved in burying a child who is believed to be commuting between this world and the world of the dead.

Also, like Wiru sorrow-names, death-prevention names in Akan involve concealed talk or indirectness that people outside the social network of the name-giver and name receiver may not understand.
Akan Death-Prevention Names 169

However, unlike Wiru penthonyms, Akan death-prevention names do not call for revenge.

Needham (1964) writes about death-names among the Temer (a Malayan people of middle Borneo) where a death-name is prefixed to the personal name at the death of a close relative. For example, if a man called Cului loses his first-born child, he assumes the name Uyung and becomes known as Uyung Cului. If it is the forth-born child who dies, then he will be called Sawang. Cului. Such mourning-names or deathnames signify the disruption death brings to the collective culture of the Temer. Thus, the mourning-names are applied to signify how death disrupts the solidarity relations in the society.

Needham (1965) notes that among the Penan (Malayan) people may change their names at the death of a parent or a first born. According to Needham there is a significant relationship between the existence of death-names and a form or quality of solidarity associated with the society. Such names thus depend, in part, on how the solidarity relationships traditional among the Penan society are retained.

In Akan society, it is not a common practice for people who already have names to take the name of a deceased relative. However, like the Lambas of Zimbabwe (Doke 1931), it is common to name a newborn after a dead person with the view that the child will take after the dead person.

Akan death-prevention names, like those of the Hausa, the Luo, and the Yoruba may be derogatory and may refer to poverty, animals (usually dangerous or destructive animals like snakes, goats, or some kinds of birds), inanimate objects (Crane 1982), names of strangers or "immigrants" who live on Akan land (especially the Frafra, Dagarti, Wangara from Northern Ghana and Mossi, an ethnic group of Burkina Faso), slavery, names of low-paid jobs such as trash collection, and death.

The communicative strategy employed by this kind of naming involves some indirectness, - especially sarcasm and satire (Obeng 1994b). On the surface, the names given by the biological parents or birth-attendants may insult, ridicule, question, or reprimand the child. The name may even suggest that the child is not wanted. In reality, however, the names are meant to show how much the child is wanted and loved. 


\section{Names 46.3 (September 1998)}

Unlike those of the Temer and Penan, Akan death-prevention names do not refer to human genealogical connections. They do not show any family relations in the society. Thus, unlike "normal" Akan names, death-prevention names shed no light on relations of consanguinity, marriage, or descent.

In addition to a death-prevention name, children are also given a proper name but they are rarely addressed (or referred to) by the proper name. In most cases, the proper name may not even be known to nonimmediate family members because addressing the children by the proper name may unveil their real identity, thereby resulting in their death.

We can conclude, then, that death-prevention and related names epitomize cultural ideas and values as well as the wishes of the society which gives them. Societies create such names to help deal with their overall psychological and socio-cultural experiences. The names help them to deal with the emotions associated with the loss of a loved one and grief associated with such a loss.

Furthermore, the names are created to help members of a society to speak the unspeakable. Thus, in Akan society it is considered rude to speak in a command form to the ancestors and the members of the spirit world because they have a higher status than the living. However, through death-prevention names, the name-givers are able to communicate with them in a command form as evidenced by the verbs' being in the imperative mood.

\section{Methodology}

The data consist of transcripts of relevant portions of tape recorded informal interviews conducted by me and an Akan native speaker assistant, Papa Yaw, in the summer of 1995. Twenty-four persons, between the ages of forty-five and seventy, were interviewed. ${ }^{5}$ All the interviewees bore death-prevention names and all were from Asuom, Ghana. The questions dealt with what their names meant, why the names were given, how they felt about their name (that is, whether they like the name), whether they would give the name to or have already passed it on to their children, and society's attitude toward the name. ${ }^{6}$

The responses given to the questions were remarkably similar. Each of the 24 interviewees ${ }^{7}$ (the name-bearers) have not given and will not give such names to their children. They indicated that they like their
Akan Death-Prevention Names 171

names because the names make them special by telling society how important they were to their parents. The interviewees also claimed that when they were children, people treated them with much more respect than they did other children because they were either their parents' (especially their mother's) only children or they belonged to a small nuclear family. Eighteen felt they would have died had they not been given the death-prevention names (Interestingly, the six who did not feel that way were all younger and had been formally educated). Three of the interviewees said they had been ridiculed by other people-something which they claim never happened when they were growing up-but it really did not bother them because they felt the ridicule was certainly (their emphasis) due to ignorance of Akan culture. All the interviewees believed that their names communicate strong messages and are relevant to members of their generation.

The responses were analyzed in two ways: pragmatically and structurally. Pragmatically, the content and meanings of the deathprevention names were examined and the names classified according to the kind of message(s) carried by the names. Thus the analysis is ethnolinguistic in nature.

Furthermore, since the study shows how language provides information about the name-givers' and name-bearers' social networks and how sociocultural needs are reflected in the naming system it is sociolinguistic as well.

In addition, the names were analyzed structurally by segmenting and classifying them according to their morphosyntactic composition. The names turned out to be simple or complex. For the names with simple structure, I identified the roots and affixes and the meanings. I classified those with a complex structure into phrases, incomplete sentences and complete sentences. The names with sentential structures were subclassified into declaratives, questions, and commands.

\section{Content of Death-Prevention Names}

The content of the death-prevention names allows them to be classified into one of seven main groups, based upon strangers' or migrants' names (5 names); destructive or dangerous animals (4 names); objects or persons associated with low status jobs or the names of such jobs (4 names); filthy places or objects (4 names); tabooed objects ( 3 names); expressions of emotions (10 names); and requests (5 names). 


\section{Strangers' or Migrants' Names}

These names are usually the names of ethnic groups from northern Ghana or from other West African countries, notably Nigeria, Burkina Faso, Mali, and Niger. These are shown in table 1.

Table 1. Migrant Death-Prevention Names

\begin{tabular}{ll}
\hline Name & Meaning \\
Wangara & A person from the Wali ethnic group \\
Sokoto & A town in northern Nigeria \\
Baasare & A northern Ghanaian ethnic group \\
Moosi & A group of people from Burkina Faso \\
Dankate & A person from the Dagarti ethnic group \\
\hline
\end{tabular}

One of the reasons given for the use of migrant names is the fact that the parents want to hide a child's identity from the spiritual parents and the use of a non-Akan name helps to make the child "invisible."

The Akan perception of strangers and migrants is significant in this naming practice. This perception is summed up in the following adages cited by some of the interviewees: Ohoho na owe akoko a, n'ani abo 'It is the stranger who eats the blind chicken'; Ohoho ani akeseakese nso enhu hwee 'The stranger's eyes are big yet they do not see well'; Ohoho te se abofra 'A stranger is like a child'. Thus, strangers are seen as being ignorant no matter how educated or intelligent (having big eyes) they are. To be classified as a stranger by one's own people is therefore being seen by them as ignorant, pitiful, childish or strange. Like a child, a stranger acts contrary to adult Akan norms of behavior. A child who gets such an alien name is therefore being told to behave himself by "staying" and acting as a proper Akan in order to be accepted as a true Akan. Failure to adhere to Akan norms results in the child's being seen as a stranger. It is thought that because every Akan wants to be respected (Animguasee mfata okanniba 'Disgrace does not befit the Akan born') the child will behave well and thus live and be accepted as a true Akan. Furthermore, in view of the fact that most migrants hold menial jobs that do not receive much respect, giving the child such a name shames him by implicitly making it known to him that his actions are not respected. This, it is thought, discourages the child from repeatedly going out of and coming into this world.

\section{Destructive and Dangerous Animals}

Death-prevention names referring to destructive or dangerous animals are shown in table 2 .

Table 2. Destructive or Dangerous Animals

\begin{tabular}{ll}
\hline Name & Meaning \\
Owo & snake \\
Akroma & hawk \\
Nanka & path adder \\
Abirekyieba & kid (calf of a goat) \\
\hline
\end{tabular}

Owo ' snake' and Nanka ' path adder' have the power to kill and thus cause grief in a family. In the same way, a child who comes into and goes out of the lives of its parents causes them to grieve and therefore deserves such a name. Akroma ' hawk' is the greatest enemy of poultry farmers, who keep free-range birds, because it catches and eats the chicks. The hawk is a nuisance because it causes farmers financial hardship. A child who is born, admired, and cared for but dies causes its parents financial loss and emotional stress.

Goats, also kept on the free range, are known to be destructive. Their kids are even more destructive. By naming a child Abirekyieba 'kid of a goat', the Akan are acknowledging the destructive potential of the child and its spiritual parents, especially their ability to ruin the biological parents' financial situation.

\section{Low Status Jobs, Objects \& Persons}

Names that fall under this category refer to persons or objects that perform important services in the Akan society but are given neither respect nor recognition. These are shown in table 3 .

Table 3. Death-Prevention Names Relating to Low Status Jobs, Objects or Persons

\begin{tabular}{ll}
\hline Name & Meaning \\
Kaya & carrier of load \\
Wuruwa & carrier of water \\
Kuntu & a stick for trapping animals \\
Donko & slave \\
\hline
\end{tabular}




\section{Names 46.3 (September 1998)}

In Akan society, load carriers do a great deal of work yet they are neither respected nor properly paid. In fact, their services are often not even appreciated. Water carriers, like load carriers, are very low on the Akan social scale. Wuruwa 'water' is borrowed from Hausa, a Chadic language spoken in Nigeria and Niger. In the past, most water carriers in Akan areas were from neighboring West African countries.

Kuntu is a stick used to trap and kill bush animals. Under normal circumstances, such a "useful" object would be thought of well; however, the Akan adage Enye wuramnam kakra a mewe nti na merebefre kuntu se wofa 'I'm not going to call kuntu "uncle" despite the fact that it helps trap and catch animals' suggests that it is not. By this, the Akan are suggesting that life can go on without meat so the kuntu is expendable. A child named Kuntu is therefore being told, sarcastically, that life can go on without him.

In Akan society, although slaves were eventually assimilated into their master's lineages, it was common to take their services for granted and not accord them recognition for their hard work. Children given any of the names in this category are therefore being reminded that although they may be of high spiritual parentage, or they may sometimes provide service for their parents, society has a low opinion of them and their present action is detestable and a change of action in the right direction (life) is expected of them.

It bears repeating that by giving these death-prevention names parents are putting on a brave face for their previous losses and seeking their children's survival and well-being even though the names themselves, at face value, imply a lack of worth or respect. Thus, verbal indirectness is at work (Obeng 1994b). The surface meaning of the utterance (the name) appears to be telling the infants that life can go on without them when in reality the name-givers are appealing to the infants to live. The obvious love between parents and children renders this disguise discourse transparent. Thus, the indirectness involved is conventionalized in Akan society.

\section{Filthy Places or Objects}

The names in this category are shown in table 4.
Akan Death-Prevention Names 175

Table 4. Death-Prevention Names Relating to Filthy Places or Objects

\begin{tabular}{ll}
\hline Name & Meaning \\
Sumina & trash or incinerator \\
Suminaba & child of trash $\sim$ child of incinerator \\
Ntomago & rag \\
Bonka & gutter $\sim$ it smells \\
\hline
\end{tabular}

In Akan society, trash is kept at the outskirts of the town; keeping refuse in or near the home is unclean. To be called Trash or Child-oftrash therefore suggests a lack of personal respect and indicates that your place is not in the home but at the trash dump. Anyone who causes financial drain on others, who makes them grieve or disturbs them emotionally, is comparable to trash and thus is not wanted.

Like refuse, sewers (which until recently were open), had a terrible odor from the waste and filth they carried. Children with such death names are likened to gutters because they are seen to be in transit and what they bring is nothing but filth.

Although the Akan sometimes find a rag or a discarded piece of cloth useful as a pad when carrying a load on the head, rags are not properly cared for as one would care for a new cloth. By naming a child Ntomago 'rag' the parents are suggesting that they are aware of the fact that the enjoyment they have in the child is temporary because they know that it will die and thus will be of no value.

\section{Tabooed Objects}

These names are shown in table 5 .

Table 5. Death-Prevention Names relating to Tabooed Objects

\begin{tabular}{ll}
\hline Name & Meaning \\
Praye & broom \\
Waduro & mortar \\
Woma & pestle \\
\hline
\end{tabular}

Even though these items are indispensable in Akan homes, it is a taboo to mention them by name. Waduro 'mortar' and Woma 'pestle' are used in pounding the staple food, fufu. Since most Akans have fufu regularly, 


\section{Names 46.3 (September 1998)}

waduro and woma are essential objects. Like the mortar and pestle, brooms are also very useful. They are symbols of cleanliness and of spiritualism, because it is thought that evil spirits commute on brooms.

In Obeng (1994a), I noted that it is a taboo to mention waduro, woma or praye and so one does not request them by name but may either refer to them as ammisa 'that which should not be asked for' or ammodin 'an unmentionable'. Mentioning them by name may invoke the spirit thought to be inherent in them. Another option for the requester is simply to take them without asking permission, use them, and return them to the owner. ${ }^{8}$

In naming a child after any of these tabooed items, the child's parents are acknowledging that they value the child and yet dislike its coming into and going out of their lives. The parents are by these names also acknowledging their awareness of the child's connection with the spiritual world and how detestable or unspeakable that is to them; the name thus also expresses the wish of the child's parents to break the connection with the spirit world so that the child will live and be addressed by a name that is mentionable.

\section{Expression of Emotions}

The ten death-prevention names expressing some form of emotion are shown in table 6 below. Although the specific emotions are difficult to identify, they generally have to do with anger, frustration, ridicle, pity, sadness or loss.

Table 6. Death-Prevention Names Expressing Emotions

\begin{tabular}{ll} 
Name & \multicolumn{1}{c}{ Meaning } \\
Kwandaho & There is the road 'Leave! You may leave! \\
Sieamono & Bury that one alive! \\
Beyeeden? & What did you come to do? \\
Pewoayeden? & Why should (I) look for you? \\
Semereka & If I should tell.... \\
Owuompe & Death does not like (that one). \\
Obimpe & No one likes (that one). \\
Onibie & That one has no one. \\
Ababio & That one has come again. \\
Bewieasee & In the end....
\end{tabular}

A couple who names their child Kwandaho 'You may leave' are, through the name, showing their anger and frustration. They are, in effect, via the name, informing the child and its spiritual parents that their actions deserve neither sympathy nor empathy since they will not be appreciated by the child. If the child will die (as it always does), they will be left with a sense of loss and sorrow so why should they pretend to want the child to stay?

Sieamono involves even more severe anger and frustration. By giving this name, the parents are telling the child that no time will be wasted in its burial should it show any sign of dying because the gravedigger has already been given the order to proceed with the burial.

With Beyeeden 'What did you come to do?' and Pewoayeden 'Why should I look for you?' the parents are telling the child that in view of its actions there is no need for them to waste their time, energy or money on it. They are angry and frustrated because they think the child has come into their lives to taunt them and to cause misery. They will therefore not waste their time to cherish or nurture it knowing very well that the child has come merely to cause grief.

Names like Obimpe and Owuompe are meant to ridicule the namebearer. In Akan semiotics (especially in nonverbal communication involving cloth and sculptures) death is emphasized as the end of all life, so naming a child Owuompe 'Death does not like him' (that is, the child is rejected by death) has strong communicative implications. It could suggest that the child, by its actions, is unacceptable even to death. If death does not accept it, then it obviously lives forever. Thus, although this name ridicules, it attempts to throw dust in the eyes of death so that death will spare the child's life and the parents' agony. In naming a child Obimpe 'No one likes (that one)' the parents of the child are, again through ridicule, shaming the child so that it will behave properly.

Onibie depicts the pitiful state of childlessness whereas Bewieasee reveals a couple's anger and loss, and shows how ungrateful they feel the child is, given the love they may have showed towards it at birth.

The functions of the names considered so far suggest that the naming process provides an indication of the emotional or psychological state of the namers (Cialdini, Finch \& Maralou 1989). In particular, the names reflect particular emotions so that such features as negative emotional valance and affect may be expressed through language (Lang \& Newhagen 1994). 


\section{Requests}

Through death-prevention names, parents may make direct or indirect requests to the child, to God, or to whoever has control over the life of the child. The verbs in the direct requests are in the imperative mood as in the direct requests Oyinka 'This one should remain! May this (one) remain' and Bagyina 'If you've come, stay.' By giving children such names, biological parents are thus able to communicate their feelings, desires and needs to other members of Akan society, including the child's spiritual parents.

Among the death-prevention names which make indirect requests are Asaaseasa 'Land is finished', Sikayepena, 'Money is difficult to find', and Adeeyepena 'Wealth is difficult to find'. As with other forms of indirectness, such names serve two illocutionary functions since they involve performing an illocutionary act indirectly by way of another act (Searle 1975). Knowledge of background information, especially of the cultural background of the participants, is necessary for understanding the indirectness involved. With regard to Asaaseasa one has to know how the Akan value land, the kind of land being talked about (in this case, graveyard or burial ground), and the relevance of 'the act of land being finished' to the speaker and to the bearer of the name. If there is no more burial ground, then one must live because no one wants their corpse to be left unburied. Knowledge of the overall context in which such a request may be made is necessary for an understanding of the indirectness involved in such names. All the names under this category have cmotional undertones and convey a sense of loss or of need. They are shown in table 7 .

Table 7. Death-Prevention Names Relating to Requests

\begin{tabular}{ll}
\hline Name & Meaning \\
Adeeyepena & Wealth is difficult to find. \\
Asaaseasa & Land is finished. \\
Bagyina & If you've come, stay. \\
Oyinka & This one should remain. \\
Sikayepena & Money is difficult to find. \\
\hline
\end{tabular}

Although Sikayepena and Adeeyepena are, on the surface, statements about the difficulty involved in acquiring money and wealth, in reality they are utterances meant to draw the name-bearer's attention to the difficulty its biological parents went through prior to its birth (including those of previous births) or are still going through and requesting the name-bearer to live because no one wants to throw money down the drain.

Morpho-Syntactic Structure of Death-Prevention Names

Based on their morphosyntactic structure, Akan death-prevention names may be classified into simple and complex names. The simple names consist of either a root alone or a root with an affix or affixes. The complex names may be classified into phrases (usually possessive constructions), incomplete sentences, and complete sentences.

\section{Simple Death-Prevention Names}

Table 8 below shows the morphological structure of the names.

Table 8. Simple Death-Prevention Names

\begin{tabular}{llll}
\hline Name & $\begin{array}{c}\text { Nominalizing } \\
\text { Prefix }\end{array}$ & Root & Nominalizing \\
& O- & wo 'pierce' & - \\
Owo 'snake' & - & kuntu 'bend & - \\
Kuntu 'stick' & A- & koro 'go' & - ma \\
Akroma 'hawk' & O- & wu 'die' & - o \\
Owuo 'death' & O- & hi 'shrink' & - a \\
Ohia 'poverty' & - & donko 'slave' & - \\
Donko 'slave' & - & kaya 'carry' & - \\
Kaya 'load carrier' & - & fra 'mix' & - ma \\
Mframa 'wind' & M- & Dankate 'Dagarti' & - \\
Dankate 'Dagarti' & - & tope 'huge' & - \\
Otope 'giant snail' & O- & Moosi 'Mossi' & - \\
Moosi 'Mossi' & - &
\end{tabular}

\section{Complex Death-Prevention Names}

Phrase (Possessive Constructions)

The names in this category have the structure $\{X+$ Child $\}$ where $\mathrm{X}$ is the possessor, since, in all Akan possessive constructions, the possessor precedes the possessed. Examples are Suminaba 'child of trash' 'child of incinerator'; Osamanba 'child of a ghost'; and Abirekyieba 'kid, child of a goat'. These are shown in table 9. 
Table 9. Complex Death-Prevention Names-Possessive Constructions

\begin{tabular}{lll}
\hline Name & Possessor & Possessed \\
$\begin{array}{l}\text { Suminaba 'child of incinerator' } \\
\text { sumina 'incinerator' }\end{array}$ & ba 'child' \\
$\begin{array}{ll}\text { Osamanba 'child of a ghost' } \\
\text { obirekyieba 'child of a goat' }\end{array}$ & $\begin{array}{l}\text { abirekyie 'goat' } \\
\text { ba 'child' }\end{array}$ & ba 'child' \\
\hline
\end{tabular}

Sentential Death-Prevention Names

The names with sentential structures fall into two sub-categories: complete and incomplete. Complete may be further divided into commands, declaratives, and questions. These are shown in tables 10, 11 and 12 , respectively.

Except Akoneaba, which is a compound sentence (table 12), all of these names have the simple structure noun phrase plus verb phrase.

\section{Death-Prevention Names With Command Sentence Structure}

Three names were of this form. Of these Kwandaho and Oyinka are direct commands and Sieamono is an indirect command. Their structures are shown below.

Table 10. Names of Command Sentence Structure

\begin{tabular}{|c|c|c|c|c|c|}
\hline Name & Structl & & & & \\
\hline $\begin{array}{l}\text { Kwandaho } \\
\text { 'There is the road'. } \\
\text { 'You may leave'. 'Leave'. }\end{array}$ & $\begin{array}{l}\text { kwan } \\
\text { road } \\
\mathbf{N}\end{array}$ & + & $\begin{array}{l}\mathrm{da} \\
\text { lie } \\
\mathrm{V}\end{array}$ & + & $\begin{array}{l}\text { ho } \\
\text { there } \\
\text { Adv }\end{array}$ \\
\hline $\begin{array}{l}\text { Oyinka } \\
\text { 'This (one) should remain'. } \\
\text { 'May this (one) remain'. }\end{array}$ & $\begin{array}{l}\text { oyi } \\
\text { this } \\
\mathrm{N}\end{array}$ & + & $\begin{array}{l}\text { n } \\
\text { should } \\
\text { M Aux }\end{array}$ & & $\begin{array}{l}\mathrm{ka} \\
\text { remain } \\
\mathrm{V}\end{array}$ \\
\hline $\begin{array}{l}\text { Sieamono } \\
\text { 'Bury that one alive'. }\end{array}$ & $\begin{array}{l}\text { sie } \\
\text { bury } \\
\text { V }\end{array}$ & + & $\begin{array}{l}\text { no } \\
\text { that one } \\
N\end{array}$ & & $\begin{array}{l}\text { amono } \\
\text { alive } \\
\text { A }\end{array}$ \\
\hline
\end{tabular}

With Kwandaho the command is being given directly to the child, who may leave the world if he chooses because no one will prevent his leaving. Oyinka is a request in the form of a directive. The child's spiritual parents are being requested to let him remain on earth. With Sieamono the command is being given to a third person-presumably the grave digger-to bury the child 'alive' because it will not survive.
Table 11. Sentential Death-Prevention Names with Declarative Structure

\begin{tabular}{|c|c|c|c|}
\hline & Structure & & \\
\hline $\begin{array}{l}\text { Asaaseasa } \\
\text { 'Land has finished'. }\end{array}$ & $\begin{array}{l}\text { Asaase } \\
\mathrm{N} \\
\text { land }\end{array}$ & $\begin{array}{l}\text { a } \\
\text { Mod Aux } \\
\text { has }\end{array}$ & $\begin{array}{l}\text { sa } \\
\mathrm{V} \\
\text { finished }\end{array}$ \\
\hline $\begin{array}{l}\text { Onibie } \\
\text { 'He has no one'. }\end{array}$ & $\begin{array}{l}\mathrm{O} \\
\text { he } \\
\mathrm{N}\end{array}$ & $\begin{array}{l}\text { ni } \\
\text { not have } \\
\text { Neg V }\end{array}$ & $\begin{array}{l}\text { obi } \\
\text { no one } \\
\mathrm{N}\end{array}$ \\
\hline $\begin{array}{l}\text { Ababio } \\
\text { 'It has come again'. }\end{array}$ & $\begin{array}{l}\text { A } \\
\text { It } \\
\text { N }\end{array}$ & $\begin{array}{l}\text { ba } \\
\text { come } \\
\mathrm{V}\end{array}$ & $\begin{array}{l}\text { bio } \\
\text { again } \\
\text { Adv }\end{array}$ \\
\hline $\begin{array}{l}\text { Owuompe } \\
\text { 'Death does not like (that one)'. }\end{array}$ & $\begin{array}{l}\text { owuo } \\
\text { death } \\
\mathrm{N}\end{array}$ & $\begin{array}{l}\mathrm{m} \\
\text { not } \\
\text { Neg }\end{array}$ & $\begin{array}{l}\text { pe } \\
\text { like } \\
\mathrm{V}\end{array}$ \\
\hline $\begin{array}{l}\text { Obimpe } \\
\text { 'No one likes (that one)'. }\end{array}$ & $\begin{array}{l}\text { obi } \\
\text { someone } \\
\mathrm{N}\end{array}$ & $\begin{array}{l}\text { m } \\
\text { not } \\
\text { Neg }\end{array}$ & $\begin{array}{l}\text { bio } \\
\text { like } \\
\mathrm{V}\end{array}$ \\
\hline $\begin{array}{l}\text { Bonka } \\
\text { 'It smells'. }\end{array}$ & $\begin{array}{l}\text { E* } \\
\text { it } \\
\text { Pro }\end{array}$ & $\begin{array}{l}\text { bo } \\
\text { hits } \\
\text { V }\end{array}$ & $\begin{array}{l}\text { nka } \\
\text { smell } \\
\mathrm{N}\end{array}$ \\
\hline $\begin{array}{l}\text { Sikayepena } \\
\text { 'Money is difficult to find'. }\end{array}$ & $\begin{array}{l}\text { siki } \\
\text { money } \\
\mathrm{N}\end{array}$ & $\begin{array}{l}\text { ye }+ \text { pe } \\
\text { is + seek } \\
\text { Aux }+V\end{array}$ & $\begin{array}{l}\text { na } \\
\text { difficult } \\
\text { A }\end{array}$ \\
\hline $\begin{array}{l}\text { Adeeyepena } \\
\text { 'Wealth is difficult to find'. }\end{array}$ & $\begin{array}{l}\text { Adee } \\
\text { thing } \\
\mathrm{N}\end{array}$ & $\begin{array}{l}\text { ye }+ \text { pe } \\
\text { is }+ \text { seek } \\
\text { Aux }+V\end{array}$ & $\begin{array}{l}\text { na } \\
\text { difficult } \\
\text { difficult }\end{array}$ \\
\hline $\begin{array}{l}\text { Akoneaba } \\
\text { 'The one who goes and comes'. }\end{array}$ & $\begin{array}{l}a+\text { ko } \\
\text { it go } \\
N P+V P\end{array}$ & $\begin{array}{l}\text { ne } \\
\text { and } \\
\text { Co }\end{array}$ & $\begin{array}{l}a+b a \\
\text { it come } \\
N P+V P\end{array}$ \\
\hline
\end{tabular}

*The subject is deleted in the surface structure.

Table 12. Death-Prevention Names With Question Structure

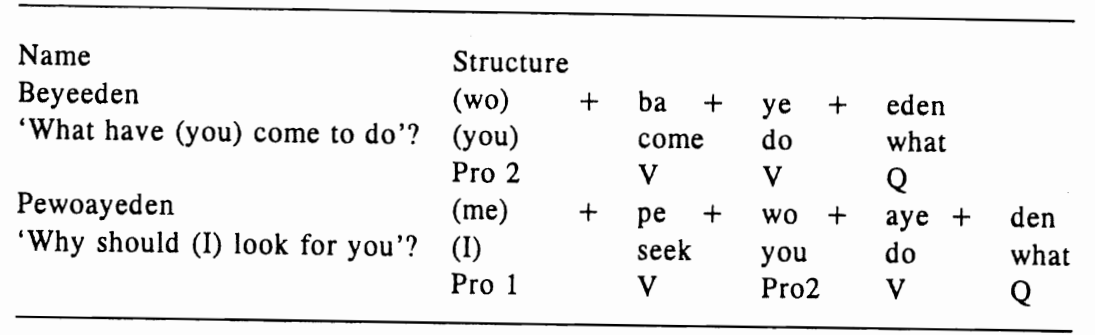


The names here ask the bearer a question intended to show the frustration of the biological parents. In each of these examples, there is no overt subject. In Beyeeden the underlying subject wo 'you' and in Pewoayeden the underlying subject $m e$ ' $I$ ' are deleted in the surface structure.

Death-Prevention Names With Incomplete Sentence Structure

Names in this category have the structure of incomplete sentences. The two examples whose structures are provided below are subordinate clauses; Semereka is a conditional clause and Bewieasee is an adverbial clause.

Table 13. Names With Incomplete Sentence Structure

\begin{tabular}{|c|c|c|c|c|c|c|c|}
\hline \multirow{3}{*}{\begin{tabular}{l}
\multicolumn{1}{c}{ Name } \\
Semereka \\
'If I should tell....'
\end{tabular}} & \multicolumn{7}{|c|}{ Structure } \\
\hline & se & + & $\mathrm{me}$ & + & re & + & $\mathrm{ka}$ \\
\hline & if & & I & & Prog & & tell \\
\hline \multirow{4}{*}{$\begin{array}{l}\text { Bewieasee } \\
\text { 'In the end....' }\end{array}$} & Cond & & $\mathrm{N}$ & & Aux & & V \\
\hline & e & + & be & + & wie & + & asee \\
\hline & (it) & & will & & finish & & end \\
\hline & $\mathrm{N}$ & & Aux & & $\mathrm{V}$ & & $\mathrm{Adv}$ \\
\hline
\end{tabular}

The full form of Semereka could be Semereka m'amanehunu akyere wo a, anka wobegyae me haw 'If I should tell you my problems or frustrations you would stop frustrating me further'. Semereka is therefore part of a larger subordinate clause "If I should tell you my problems." Bewieasee could be followed by several expressions of loss and pity. For example, it could be followed by the expression na wafiri yen nsa 'we would lose him (that is, he would die).

\section{Discussion and Conclusions}

This study has shown that Akan death-prevention names, like those in other societies, are not mere linguistic expressions or labels but are culturally meaningful as indicators of real life experiences of a people; the names reflect emotional states, needs and desires, circumstances surrounding birth, belief systems, and thoughts and ideas. It has also shown the relevance of names as insights into society. The death- prevention names provide information about the name-givers' emotions and states of mind at the time the names were given.

Death-prevention names show society's dual reaction to death. On the one hand, death is conceived as a powerful entity to whom one should appeal or fear and with whom one should plead, and, if possible, avoid. On the other hand, despite its destructive capabilities, the namegivers are, through the names, able to treat death with defiance. As was pointed out in the core sections of this paper, the Akan may show their frustration and anger with death and with the child thought to be commuting between the physical and spiritual worlds, by naming the child Kwandaho 'You may leave!' or Pewoayeden 'Why should I look for you'. A similar situation is found among the Igbo of Nigeria who show their defiance of death by naming a child Onwuma 'Death may do as he pleases' or Onwudinjo 'Death is unkind'. Thus, although the concept of death may inspire fear, a sense of loss, helplessness, and gloom, it could also inspire anger, frustration and defiance.

Furthermore, death-prevention names reveal both the humane and the evil faces of death. On the one hand, the names reveal death's ability to spare one's life, to show compassion or to pardon; on the other hand, they depict death's ruthlessness.

This work has also shown that even though the Akan recognize the power of death, they are also aware of the fact that death is not allknowing because through naming, it can be tricked by humans. Humans' ability to trick death is also noted by Modupe (1972) in Yoruba society. Among the Yoruba, the name Kusmo means 'Death could not recognize him'.

Through death-prevention names, the Akan are able to lament the death of children who may have died earlier. The names thus pave the way for the name-givers to pay respect to the dead.

In Akan society, as in other African, Asian and American societies, death-names or death-prevention names refer to the communal or collective culture in which the loss of an individual affects the entire community. For example, as with the Penan or Temer, in Akan society, there is a significant relationship between death-prevention names or mourning-names and social solidarity and such names show the extent of disruption visited upon the society when one of its members dies. 


\section{Names 46.3 (September 1998)}

In addition to showing the relationship between linguistic expressions (names) and the context of their use, including the time and space of the discourse, the study has revealed the insights provided when ethnographic knowledge illuminates the ways in which language contributes to social life and how social interaction influences language. The names are deeply rooted in the language and culture of the Akan and it is impossible to fully understand the names without a thorough knowledge of Akan society. This point about the ways in which language and culture go hand in hand is also articulated by de Klerk and Bosch (1996), Oduyoye (1987), Suzman (1994), and many others.

The names also reflect the loss, emotional trauma, and hardship parents who suffer child mortality go through. These names and others, therefore, show how language is used to talk about culture and how culture informs language. Thus, from the death-prevention names dealt with in this paper, we see the interdependence between language and culture and realize that it is impossible to talk meaningfully about the one without the other.

Context is extremely important in understanding and using these names because the names are products of experiences undergone by the name-givers. This paper thus supports the claim made by Oyetade (1997) among others that African names reflect circumstances in the name-bearer's family. In particular, it confirms Oyetade's $(1997,178)$ assertion that "names are not given at random because of their euphony or merely because a distinguished member of the family or of the community was so named, but of a set purpose from circumstances connected with the child itself, or with reference to the family fortunes at the time."

Death-prevention names have great significance in Akan communication, especially indirect communication. By choosing a particular death-prevention name, the Akan, by addressing or calling the bearer of the name, can convey a message meant either for the name-bearer, the name-bearer's spiritual parents, or any member of Akan society. Given the nature of the indirectness involved, a sound background knowledge of Akan culture and of Akan communication strategies is essential for understanding the death-prevention names.

On the future of death-prevention names in Akan society, there is no doubt that improved medical care, Westernization, and religion

\section{Akan Death-Prevention Names 185}

(Christianity, to a large extent, and Islam, to a limited extent) have influenced the choice of Akan names. Names, like societies, are not static. In view of the fact that death-prevention names are no longer given, this study may be viewed as an "ethnographic present."

\section{Notes}

I am very grateful to my assistant Papa Yaw for helping with the data collection for this study. I am also grateful to my colleague, Mr. Edward Apenteng-Sackey of the Linguistics Department, University of Ghana, Legon, for his useful comments on the two names he provided.

1. All the examples given here are in a form of the orthography.

2. The days and day-names (male followed by female) and their associated characteristics are: Kwasiada 'Sunday' (Kwasi, Akosua 'spiritual'); Edwoada 'Monday' (Kwadwo, Adwoa 'peaceful'); Ebenada 'Tuesday' (Kwabena, Abenaa 'friendly'); Wukuada 'Wednesday' (Kwaku, Akua 'evil'); Yawoada 'Thursday' (Yaw, Yaa 'brave'); Efiada 'Friday' (Kofi, Afia 'wanderer'); Memeneda 'Saturday' (Kwame, Amma 'impregnable').

3. In Ghana, this may be called a Christian name. There are people with such English or Biblical names who are not Christians. There are also Christians who have no Biblical names.

4. In Akan society, in addition to giving a death-prevention name, several nonAkan razor cuts acting as pointers to another ethnicity may be made on the face of the child. The child therefore assumes physical and linguistic features which are non-Akan and which hide his identity from the spirits capable of killing him.

5. I found no one under the age of forty with a death-prevention name. This suggests that such names are no longer generally given, probably because of improved medical care for infants.

6. My colleague, Mr. Apenteng-Sackey provided two of the names, Sokoto and Wangara, and relevant ethnographic comments on them.

7. Although there were 24 interviewees, I have 35 names. As mentioned in note 6, two of the names were given by Mr. Apenteng-Sackey. Some of the interviewees also provided more than one name when they were asked to mention other deathprevention names known to them.

8. Such an act is not considered theft in the society given society's awareness of the communicative conventions associated with requesting such unmentionable items. 


\section{References}

Asante, M.K. 1995. The Book of African Names. Trenton: Africa World P.

Crane, L. 1982. African Names: People and Places. Urbana-Champaign: $\mathrm{U}$ of Illinois $\mathrm{P}$.

Chuks-orji, O. 1972. Names from Africa. Their Origin, Meaning, and Pronunciation. Chicago: Johnson Publishing Company Inc.

Cialdini, R.B., J.F. Finch \& E. de N. Maralou. 1989. "Strategic Selfpresentation: The Indirect Route”. In M. Cody \& M. Mclaughlin, eds., The Psychology of Tactical Communication (pp. 194-206). Clevedon: Multilingual Matters.

de Klerk, V. \& Bosch, B. 1996. Naming Practices in the Eastern Cape Province of South Africa. Names 44:167-88.

Doke, C.M. 1931. The Lambas of Northern Rhodesia: A Study of their Customs and Beliefs. London: Harrap.

Ebeogu, A. 1993. "Onomastics and the Igbo Tradition of Politics." African Languages and Cultures 6:133-146.

Lang, A.P.B. \& J. Newhagen. 1994. Categorical and Dimensional Theories of Emotion: How they Predict Memory for Television Messages. Paper presented to the Theory and Methodology Division of the Association for Education in Journalism and Mass Communication, Atlanta, GA.

Lowie, R.H. 1963. Indians of the Plains. Garden City, NY: Natural History $\mathrm{P}$.

Madubuike, I. 1974. Structure and Meaning in Igbo Names. Buffalo: State U of New York P.

.1994. A Handbook of African Names. Colorado Springs: Three Continents $\mathrm{P}$.

Needham, R. 1954. "The System of Teknonyms and Death-Names of the Penan." South Western Journal of Anthropology 10:416-431.

. 1964. “Temer Names." Journal of the Malayan Branch, Royal Asiatic Society 37:121-125.

. 1965. "Death-names and Solidarity in Penan Society." Journal of the Malayan Branch, Royal Asiatic Society 38:58-76.
Obeng, S.G. 1981. Nouns and Nominalization in Akan. Unpublished BA (Hons.) Dissertation. Legon: Linguistics Department, U of Ghana.

1994a. "Speaking the Unspeakable in Akan Discourse." Papers in Ghanaian Linguistics 9:22-36.

1994b. "Verbal Indirection in Akan Informal Discourse." Journal of Pragmatics 21:37-65.

. (in preparation). African Onomastics: A Morpho-semantic and Sociolinguistic Analyses.

Oduyoye, M. 1982. Yoruba Names: Their structure and Meaning. London: Karnak House.

Okwany, A.L. 1998. Luo Names. Paper Presented at the African Linguistics Seminar. Bloomington: Indiana University.

Opoku, A.A. 1967. Obi Kyere. Accra: Bureau of Ghana Languages.

Oyetade, A.B. 1997. "Some Place Names in Akokoland." African Languages and Cultures 10:157-180.

Sarpong, P. 1974. Ghana in Retrospect. Some Aspects of Ghanaian Culture. Accra: Ghana Publishing Corporation.

Searle J.R. 1975. "Indirect Speech Acts." In Peter Cole \& Jerry Morgan, eds., Syntax and Semantics, vol 3: Speech Acts. New York: Academic P.

Stewart, J. 1993. African Names. Names from the African Continent for Children and Adults. New York: Carol Publishing Group.

Strathern, A. 1970. "Wiru Penthonyms." Bijdragen Tot de Taal-Landen Volkenkunde 121:58-76.

Suzman, S.M. 1994. "Names as Pointers: Zulu Personal Naming Practices." Language in Society 23:253-72.

Thipa, H.M. 1983. "By their Names you shall Know them." Proceedings of the 2nd Southern African Name Congress. Pretoria: South Africa, 286-291.

Ubahakwe, E. 1981. Igbo Names:Their Structure and their Meanings. Ibadan: Daystar P.

Umunna, I. 1968. "Ibo Names and the Concept of Death." African Scholar 1:28.

Zawawi, S.M. 1993. What's in a Name? Unaitwaje? A Swahili Book of Names. Trenton: Africa World P. 